\title{
Intravascular stents: a new technique for tissue processing for histology, immunohistochemistry, and transmission electron microscopy
}

\author{
N Malik, J Gunn, C M Holt, L Shepherd, S E Francis, C M H Newman, D C Crossman, \\ D C Cumberland
}

\begin{abstract}
Background-Study of the vascular response to stent implantation has been hampered by difficulties in sectioning metal and tissue without distortion of the tissue stent interface. The metal is often removed before histochemical processing, causing a loss of arterial architecture. Histological and immunohistochemical sections should be $5 \mu \mathrm{m}$ with an intact tissue stent interface.
\end{abstract}

Objectives-To identify the most suitable cutting and grinding equipment, embedding resin, and slides for producing thin sections of stented arteries with the stent wires in situ for histological, immunohistochemical, and transmission electron microscopic (TEM) analyses.

Methods-20 balloon stainless steel stents were implanted in the coronary arteries of 10 pigs. Twenty eight days later the stented arterial segments were excised, formalin fixed, embedded in five different resins (Epon 812, LR white, T9100, T8100, and JB4), and sectioned with two different high speed saws and a grinder for histological, immunohistochemical, and TEM analyses. Five stented human arteries were obtained at necropsy and processed using the best of the reported methods.

Results-The Isomet precision saw and grinder/polisher unit reliably produced $5 \mu \mathrm{m}$ sections with most embedding resins; minimum section thickness with the horizontal saw was $400 \mu \mathrm{m}$. Resin T8100, a glycol methacrylate, enabled satisfactory sectioning, grinding, and histological (toluidine blue, haematoxylin and eosin, and trichromatic and polychromatic stains) and immunohistochemical analyses ( $\alpha$ smooth muscle actin, von Willebrand factor, vimentin, proliferating cell nuclear antigen, and CD68 (mac 387)). T9100 and T8100 embedded stented sections were suitable for ultrastructural examination with TEM. Stented human arterial sections showed preserved arterial architecture with the struts in situ.

Conclusion-This study identified the optimal methods for embedding, sawing, grinding, and slide mounting of stented arteries to achieve $5 \mu \mathrm{m}$ sections with an intact tissue metal interface, excellent surface qualities, histological and immunohistochemical staining properties, and suitability for TEM examination. The technique is applicable to experimental and clinical specimens.

(Heart 1998;80:509-516)

Keywords: stents; resin; histology; immunohistochemistry; transmission electron microscopy

The concept of an endoluminal mechanical device to hold open an artery was first introduced by Dotter, who in 1969 reported the use of such a device in the canine popliteal artery. Metallic stents are now frequently used as an adjunct to coronary balloon angioplasty. ${ }^{1-4}$ Restenosis within stents is an important clinical problem. Our understanding of the vascular reaction to stent implantation in humans has been limited by the rarity of necropsy specimens. Atherectomy specimens may offer some insights, but samples are few and fragmented. Porcine coronary artery has offered significant insights into the response to balloon angioplasty. ${ }^{5-10}$ The vascular reaction to stents may also be studied in animal models. ${ }^{11-16}$ The practical difficulties inherent in sectioning metal and tissue together without disruption of the tissue morphology have also limited analysis of the vascular response to stents. One method has been to remove the metal before histological processing causing the loss of normal vascular architecture, especially at the metal tissue interface. ${ }^{11-14} 17{ }^{18}$ Hard biological tissue, such as bone, can be embedded in plastics, sectioned with a high speed saw and ground to a thickness suitable for histological examination. ${ }^{19-22} \mathrm{~A}$ similar technique has been used to section stented arteries $(50-100 \mu \mathrm{m})$ embedded in methyl methacrylate. ${ }^{23-25} \mathrm{~A}$ direct method of sectioning methyl methacrylate embedded stented arteries has also been described. ${ }^{26}$ Sections in this study permitted some histological staining but there was no documented use of immunohistochemical techniques or transmission electron microscopy (TEM), with the struts in situ. Arterial sections for immunohistochemical processing should be at most $5 \mu \mathrm{m}$ and, as most cellular reaction to stents occurs immediately around the struts, have an intact tissue metal interface. Moreover, tissue immunoreactivity should be similar to that of paraffin embedded sections.

Our aim was to identify the most suitable cutting and grinding equipment, embedding resin, and slides for producing thin sections of stented arteries for histological, immunohistochemical, and TEM analyses, while minimising sample wastage. Finally, we tested applicability of the best techniques for processing stented human arterial specimens obtained at necropsy. 
Table 1 Clinical details of stented human necropsy specimens

\begin{tabular}{lllll}
\hline Patient & Vessel stented & Stent type & Vessel patent & Poststent time \\
\hline 1 & Coronary & AVE (AVE) & Yes & 10 minutes \\
2 & Coronary & XT (Bard) & Yes & 10 minutes \\
3 & Coronary & AVE (AVE) & Yes & 2 days \\
4 & Peripheral & Wallstent (Schneider) & No & 2 years \\
5 & Peripheral & Memotherm (Bard) & No & 1 year \\
\hline
\end{tabular}

Table 2 Embedding resins and source

\begin{tabular}{lll}
\hline Resin & Type & Source \\
\hline Epon 812 & Epoxy & TAAB Laboratories \\
LR white & Acrylic & London Resin company \\
T9100 & Methyl-methacrylate (MMA) & TAAB Laboratories \\
T8100 & Glycol-methacrylate (GMA) & TAAB Laboratories \\
JB4 & Glycol methacrylate (GMA) & TAAB Laboratories \\
\hline
\end{tabular}

\section{Materials and methods}

STENTED PORCINE CORONARY ARTERIES

Twenty balloon expandable stainless steel stents were used: 10 Palmaz-Schatz stents (Cordis, Bracknell, UK) and 10 BiodivYsio stents (Biocompatibles, Farnham, Surrey, UK) were hand crimped onto standard $3.5 \mathrm{~mm}$ coronary angioplasty balloons and deployed in the porcine coronary artery as previously described. ${ }^{27}$ Each of 10 pigs received two stents of the same type, one in the right coronary artery and one in the left anterior descending artery. Oral aspirin (300 mg) was given daily for five days. The animals were killed 28 days later. All experiments conformed with UK Home Office regulations.

STENTED HUMAN CORONARY ARTERIES

Five stented arteries from five patients were obtained at necropsy. Table 1 summarises relevant clinical details.

TISSUE COLLECTION AND FIXATION

The porcine hearts were explanted and the stented coronary arterial segments were dissected free with a minimum of surrounding tissue, flushed with saline, immersion fixed in formal saline for 24 hours, and embedded in five different resins (table 2). Coronary arteries without stents (controls) were fixed as previously described and embedded in resin or paraffin wax.

RESINS

Sawing and grinding of stented arteries can be performed only after embedding in resin. The manufacturer's recommended embedding protocol was used for each resin. For resin T8100, for example, stented tissue blocks were dehydrated in $100 \%$ (vol $/ \mathrm{vol})$ acetone and immersed in infiltrating solution (50\% benzoylperoxide with hydroxyethyl methacrylate) according to the manufacturer's instructions. A $3 \mathrm{~cm}$ long stented block required $10 \mathrm{ml}$ of infiltrating

Table 3 Comparative performance of stented arteries embedded and sectioned using the Buehler saw/grinder

\begin{tabular}{lllll}
\hline & Strength & Flushing & Histology & $\begin{array}{l}\text { Immuno- } \\
\text { histochemistry }\end{array}$ \\
\hline Epon 812 & +++ & +++ & + & None \\
LR white & +++ & +++ & + & None \\
T9100 & +++ & ++ & + & None \\
T8100 & ++ & ++ & +++ & ++ \\
JB4 & + & + & +++ & +++ \\
\hline
\end{tabular}

+++ , good; ++ , reasonable; + , poor. solution for $16-24$ hours at $4^{\circ} \mathrm{C}$. Specimens were transferred into the embedding solution (infiltrating solution plus tetramethyl aniline according to manufacturer's recommendations) after infiltration, then correctly orientated in polythene tubes (TAAB laboratories, Berkshire, UK) and covered with embedding solution. The tubes were hermetically sealed for 24 hours at $4^{\circ} \mathrm{C}$.

Softening of the resin may occur during sectioning and grinding because of prolonged contact with water. Softening was assessed by immersion of blocks $(n=3)$ of each resin in water for up to four hours, the time required to section half a stent. These tests were repeated with arterial tissue embedded in each resin $(n=3)$ and finally with stented arteries in each resin. The strength of each resin and its ability to withstand continuous flushing were graded on an arbitrary scale (table 3). Sections were also examined for damage to the arterial tissue as a result of resin shrinkage, using light microscopy, and compared with paraffin embedded arterial sections. The most suitable resin was selected for subsequent work, including stented human specimens.

\section{SECTIONING OF STENTED ARTERIES}

A horizontal rotatory saw microtome (Leica, Milton Keynes, UK) and a high speed precision saw (Isomet 2000; Buehler Krautkramer, Coventry, UK) were tested. The Leica saw microtome possesses a horizontal rotatory blade with a diamond coated edge. The Isomet saw possesses a diamond coated vertical blade and is used with the Metaserv 2000 grinder/polisher unit (Buehler). The Metaserv 2000 has two rotating wheels for grinding and polishing.

The end surface of the resin block was ground using the Metaserv 2000 grinder and fixed onto a slide using a contact adhesive (Super-attak; Loctite). The block was mounted onto the chuck of the Isomet precision saw and a $100 \mu \mathrm{m}$ section was sliced from the slide end of the resin block. The block surface was then prepared for the next section. The process was repeated to give consecutive $100 \mu \mathrm{m}$ sections affixed to each slide. Each $100 \mu \mathrm{m}$ section was ground to the required thickness using the Metaserv 2000 grinder. Abrasive paper of increasing fineness (sizes 35, 27.5, 21.8, 15.3, and $9 \mu \mathrm{m}$ ) was used to grind each section to $10-20 \mu \mathrm{m}$. Finally, sections were either polished with $3 \mu \mathrm{m}$ paper ready for morphometric analysis or ground further to $5 \mu \mathrm{m}$ using a Biothin grinder (Buehler) ready for histological and immunohistochemical staining. The stented human specimens were sectioned using the described techniques.

SLIDES

Uncoated glass slides (Shandon, Hampshire, UK), coated glass slides (poly-L-lysine coated and aminopropyltriethoxysilone (APES) coated; $\mathrm{BDH}$, Leicester, UK), and Perspex slides (Mederex, Bath, UK) were compared for efficacy of fixation to the resin embedded sections and resistance to breakage. Fixation of sections to slides was tested with and without contact adhesive (Super-attak). 
HISTOLOGICAL AND IMMUNOHISTOCHEMICAL TECHNIQUES

The following sequence (steps $\mathrm{A}-\mathrm{C}$ ) was adopted to minimise specimen wastage. Initially, the histological and immunohistochemical techniques were tested on arteries without stents embedded in each of five resins (table 2) and sectioned to $5 \mu \mathrm{m}$ using a conventional microtome (step A). The results were compared with those of paraffin embedded arterial sections, to identify changes in staining properties and immunoreactivity of the arterial tissue following resin embedding. Where appropriate, the staining methods were repeated on $5 \mu \mathrm{m}$ sections of arteries without stents embedded in resin and sectioned using the high speed saw and grinder/polisher (step B), to exclude changes in staining properties and immunoreactivity due to sawing and grinding. Finally, the histological and immunohistochemical techniques were tested on stented arterial specimens sectioned as described earlier (step C). Paraffin embedded arterial sections (not stented) were used as controls.

HISTOLOGY

Incompatibility of organic solvents with the embedding resins and Perspex slides limited the range of staining methods. We used a staining kit (Unicryl; British Biocell Int, Cardiff, UK) which included toluidine blue, haematoxylin and eosin, trichromatic (haematoxylin, silver methenamine, and light green), and polychromatic (haematoxylin, silver methenamine, light green, eosin, and safranin) stains. The manufacturer's recommended methods were used with modifications to temperature and staining time for each resin.

IMMUNOHISTOCHEMISTRY

We tested the immunological markers for $\alpha$ smooth muscle actin (Dako, Cambridge, UK), von Willebrand factor (vWF) (Dako), vimentin (Sigma, Poole, Dorset, UK), CD68 (mac 387; Dako), and proliferating cell nuclear antigen (PCNA) (clone 10; Dako). Briefly, endogenous peroxidase activity when using the avidin biotin peroxidase complex was blocked by incubation with 3\% (vol $/ \mathrm{vol}$ ) hydrogen peroxide for 30 minutes. Optimal results were achieved without pretreatment (trypsin or microwave antigen retrieval). Non-specific binding of immunoglobulin $\mathrm{G}$ was blocked by incubation with $10 \%$ (vol/vol) normal serum (as appropriate for each antibody) for 30 minutes before overnight incubation at $4^{\circ} \mathrm{C}$ with the primary antibodies at optimal dilutions ( $\alpha$ smooth muscle actin 1:100, vWF 1:100, vimentin 1:50, CD68 1:25, and PCNA 1:25). Sections were rinsed in phosphate buffered saline and incubated at room temperature with a biotinylated secondary antibody (immunoglobulin G) (Vector Laboratories, Peterborough, UK) for one hour at 1:100 dilution. The signal was enhanced by incubation with tertiary avidin biotin complex (Vector Laboratories) for one hour before detection using either New Fuchsin Red system (Dako) or diaminobenzidine (Sigma) staining as recommended by the manufacturer's protocol. Sections were counterstained with methyl green or haematoxylin. Paraffin embedded arterial sections (not stented) were used as positive controls for each antibody. Negative controls (without primary or secondary antibodies, or both) were also performed for all antibodies tested.

TRANSMISSION ELECTRON MICROSCOPE ANALYSIS Two formalin fixed, stented porcine arterial specimens were embedded in resin T8100 or T9100 and prepared for TEM. Additional treatment such as postfixation with osmium tetroxide was not performed. Thin sections $(70 \mathrm{~nm})$ from the luminal aspect of the stent wires were cut with a diamond ultramicrotome, mounted on grids, and contrasted at $21^{\circ} \mathrm{C}$ with $2 \%$ uranyl acetate in $50 \%$ (vol $/ \mathrm{vol}$ ) ethanol for 30 minutes and Reynolds lead citrate for 10 minutes. Sections were examined using a Philips 400 transmission electron microscope at $60 \mathrm{kV}$ accelerating voltage.

\section{Results}

SAWING AND GRINDING

The Leica saw microtome with embedding resins Epon 812, LR white, and T9100 produced $400 \mu \mathrm{m}$ sections of stented arteries. Attempts to obtain thinner sections resulted in loss of tissue architecture or stent wires. Minimum section thickness with intact tissue architecture was $600-800 \mu \mathrm{m}$ with the softer resins T8100 and JB4.

Consecutive sections $(80-100 \mu \mathrm{m})$ of stented arteries embedded in resins Epon 812, LR white, T9100, and T8100 were produced by the Isomet 2000 precision saw at a load of $400 \times g$ while gradually increasing the rotational speed of the blade from 600 to $1200 \mathrm{rpm}$. Disruption of the sections increased with higher and lower rotational speeds or loads. These sections were ground with the Metaserv 2000 grinder/polisher to $10-20 \mu \mathrm{m}$ without loss of tissue architecture or stent wires. On average, 12-14 sections per $15 \mathrm{~mm}$ stent were produced. Minimum section thickness achieved with resin JB4 was $400 \mu \mathrm{m}$ : it was not suitable for grinding.

Kerf loss, defined as the amount of material lost or removed from the specimen due to thickness of the blade passing through the specimen, was reduced by adopting the smallest blade. We therefore tried a selection of diamond abrasive wafering blades (Buehler), ranging from 10$18 \mathrm{~cm}$ in diameter and $80-300 \mu \mathrm{m}$ thickness. The smaller diameter also implies a thinner blade. The $18 \mathrm{~cm}(300 \mu \mathrm{m})$ blade was replaced by a $10 \mathrm{~cm}$ blade $(80 \mu \mathrm{m})$ blade. Smaller blades required a change in blade supports (flanges) from $7.6-4.4 \mathrm{~cm}$, to prevent the blade from bending or torquing during a cut. Together, these changes to the Isomet 2000 precision saw reduced kerf loss from an estimated 300$350 \mu \mathrm{m}$ to less than $100 \mu \mathrm{m}$. An important feature of the Isomet 2000 precision saw is the facility for regular blade maintenance using an integrated blade dressing mechanism. This obviates the need for time consuming dismantling and cleaning of the blade, while also improving efficiency of sectioning and minimising sample wastage. Between 28 and 30 sections per $15 \mathrm{~mm}$ stent were reproducibly obtained. 

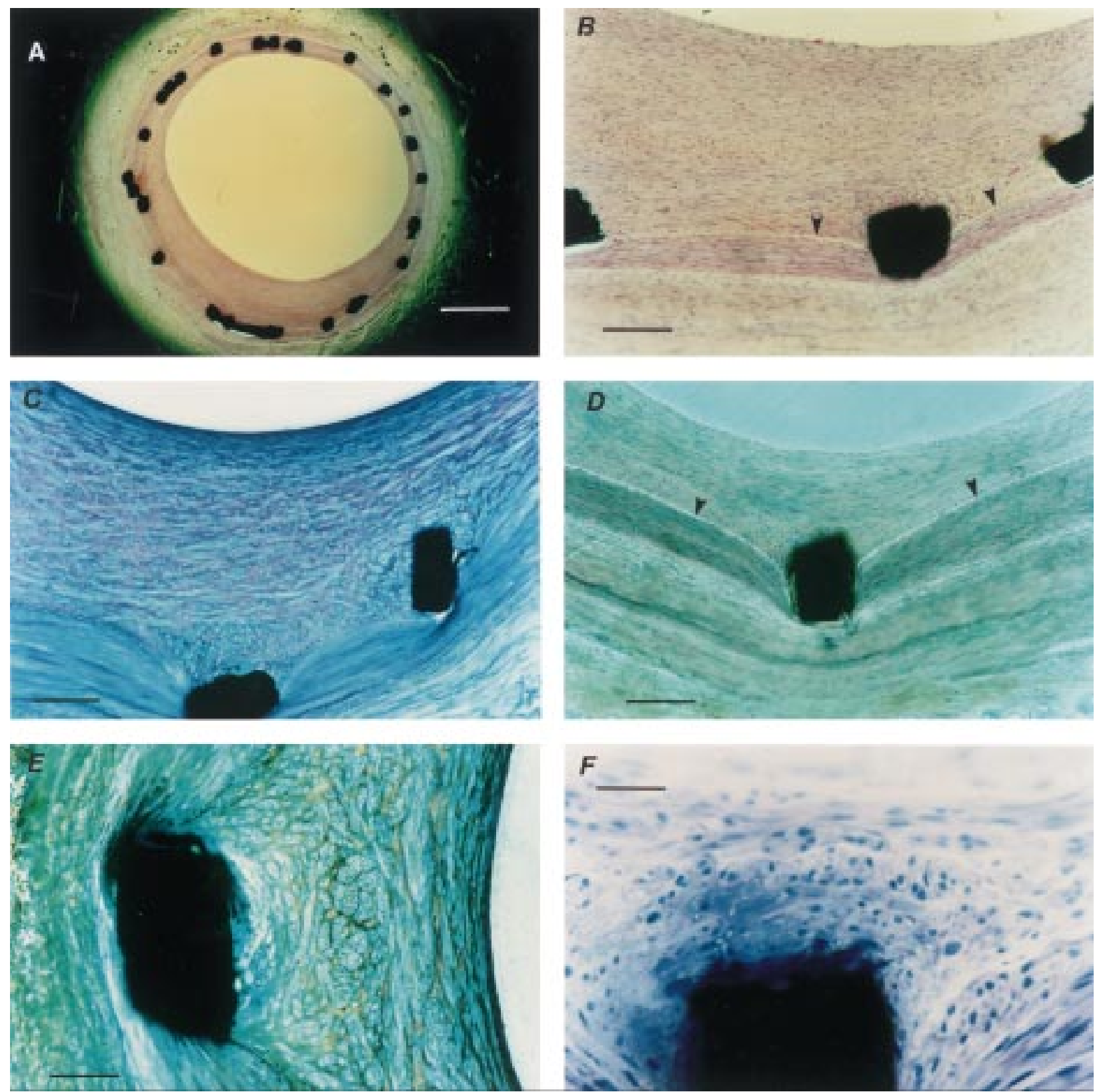

Figure 1 Histological staining of stented arterial sections. (A) Haematoxylin and eosin stained section (scale bar $=500$ um) showing preserved arterial wall architecture and stent struts in situ; and (B) at higher magnification (scale bar $=100 \mu \mathrm{m}$ ) with an intact internal elastic lamina (arrowheads). (C) Toluidine blue stained section (scale bar $=100 \mu \mathrm{m}$ ) showing varying spatial orientation of cells within the neointimal layer. (D) Trichromatic stained section (scale bar $=100 \mu \mathrm{m}$ ) showing struts in situ, preserved arterial architecture, and an intact internal elastic lamina (arrowheads); and (E) at higher magnification (scale bar $=50 \mu \mathrm{m}$ ) showing cells around the strut arranged in clusters, unlike cells nearer the lumen. (F) Haematoxylin stained section $($ scale bar $=5 \mu \mathrm{m})$ showing an intact tissue metal interface with neointimal cells around the strut arranged in clusters.

Sections of $10-20 \mu \mathrm{m}$ obtained with the Metaserv 2000 grinder, along with the finer abrasive paper, frequently had an uneven surface and thickness which gave suboptimal histochemical analysis. This problem was resolved with the portable Biothin grinder. The Biothin grinder allowed accurate and gentle grinding to produce $5 \mu \mathrm{m}$ sections in resins Epon 812, LR white, T9100, and T8100. Tissue architecture was preserved with the stent wires in situ.

SLIDES AND RESINS

Slides

Perspex slides (Mederex) were resistant to damage during sawing and grinding and, with contact adhesive (Super-attak), exhibited greater adhesion of resin embedded sections than did glass slides.

Resin

Table 3 summarises strength of the resins and their ability to withstand continuous flushing. We achieved consecutive $100 \mu \mathrm{m}$ sections of stented arteries embedded in resins Epon 812, LR white, T9100, and T8100. Tissue architecture and stent wires remained intact. Resin JB4 readily absorbed water, making it unsuitable for thin sectioning and grinding. The Metaserv 2000 grinder was used to grind the $100 \mu \mathrm{m}$ sections to $10-20 \mu \mathrm{m}$ without loss of tissue architecture or stent wires. Further grinding of 

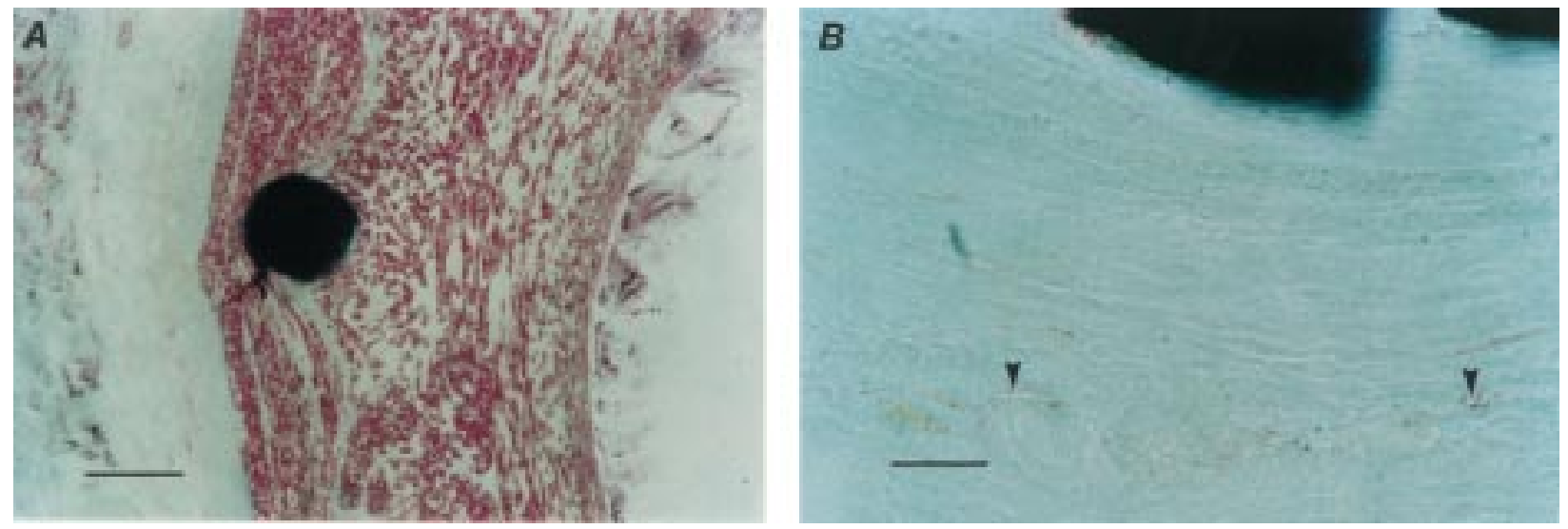

Figure 2 Immunohistochemical staining of stented arterial sections. (A) a Smooth muscle actin staining (scale bar $=100$ um): a smooth muscle actin positive cells are stained red (New Fuchsin Red), the counterstain is methyl green. All cells within the neointima, with distinctly differing spatial orientation, and media are positive for a smooth muscle actin. (B) von Willebrand Factor staining (scale bar $=50 \mu \mathrm{m}$ ): endothelium (arrowheads) of the vasa vasorum of the adventitia is stained red (New Fuchsin Red), the counterstain is methyl green.

Epon 812, LR white, T9100, and T8100 sections with the Biothin achieved adequate $5 \mu \mathrm{m}$ sections without disrupting tissue architecture or stent wires. Finally, artefactual tissue damage due to resin shrinkage was seen in Epon 812 , LR white, and T9100 embedded sections. T8100 and JB4 embedded sections were rarely associated with artefactual damage, similar to the findings obtained with paraffin sections.

HISTOLOGY, IMMUNOHISTOCHEMISTRY, AND TEM Histology

Poor staining characteristics were seen in Epon 812 , LR white, and T9100 embedded sections before deplasticisation. Staining of T8100 and JB4 with toluidine blue, haematoxylin and eosin, trichromatic, and polychromatic produced good results without prior deplasticisation. The optimal temperature for T8100 stented arterial sections was $60^{\circ} \mathrm{C}$ : this temperature significantly reduced staining time. Results of these histology stains on T8100 embedded sections are comparable with those of paraffin embedded sections (fig 1).

\section{Immunohistochemistry}

Immunohistochemical techniques on the stented arterial sections embedded in resins Epon 812, LR white, or T9100 failed to produce results without prior removal of the resin. Deplasticisation using organic solvents was incompatible with Perspex slides and was not attempted. Pretreatments (trypsinisation and/or microwave antigen retrieval) did not improve immunohistochemical staining. Sections of stented arterial tissue embedded in resins JB4 and T8100 did not require deplasticisation before immunohistochemical processing:
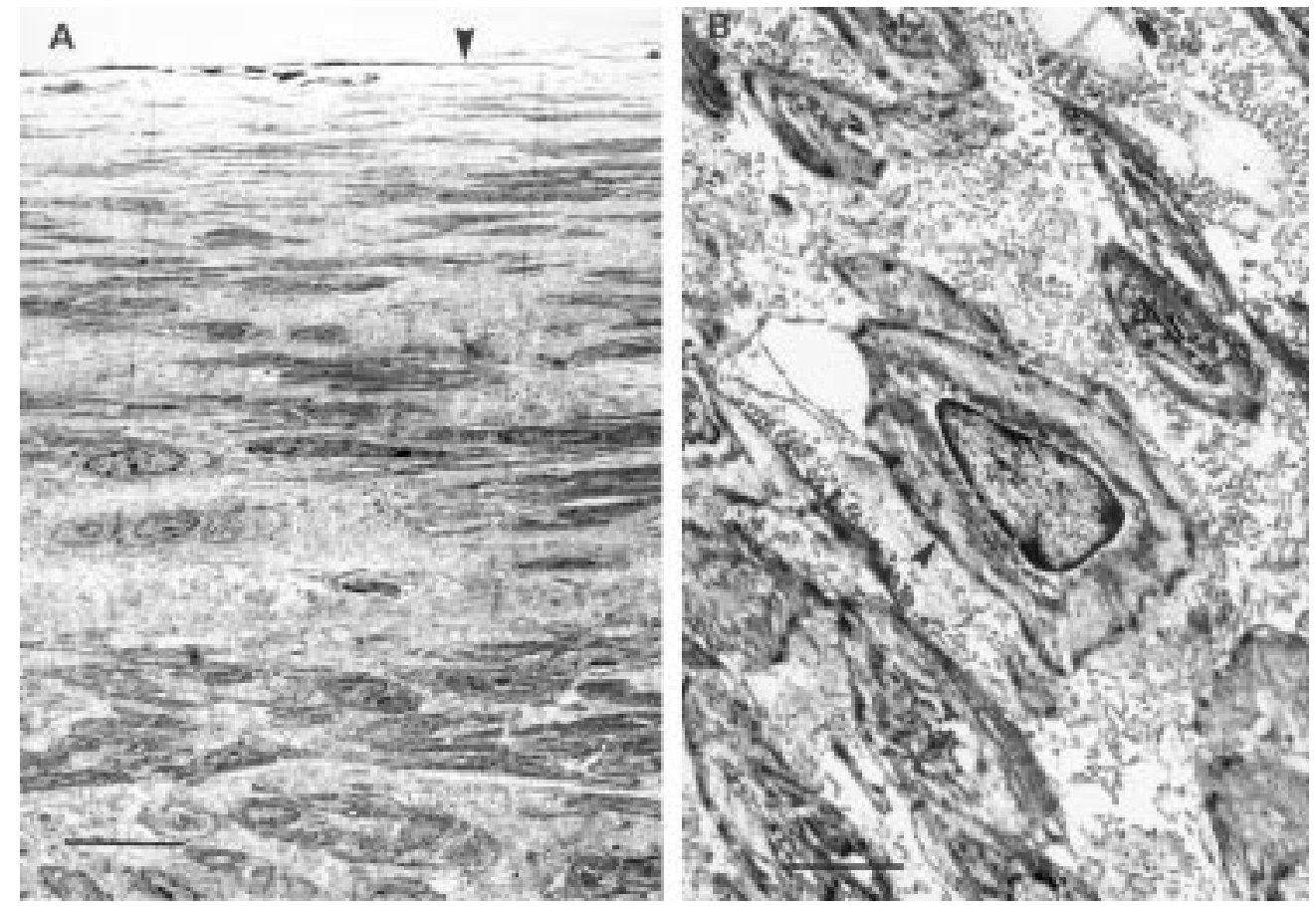

Figure 3 Transmission electron micrographs of stented coronary artery sections. (A) Neointimal layer 28 days after stenting with abundant extracellular matrix and interspersed smooth muscle cells (scale bar $=0.5 \mu \mathrm{m}$ ) arranged in distinctly different spatial orientation. Arrowhead indicates the luminal surface. (B) Phenotype of the neointimal cells is confirmed as smooth muscle cells (scale bar $=0.18 \mu \mathrm{m})$. Note characteristic cytoplasmic motor regions of these cells (arrowhead). 

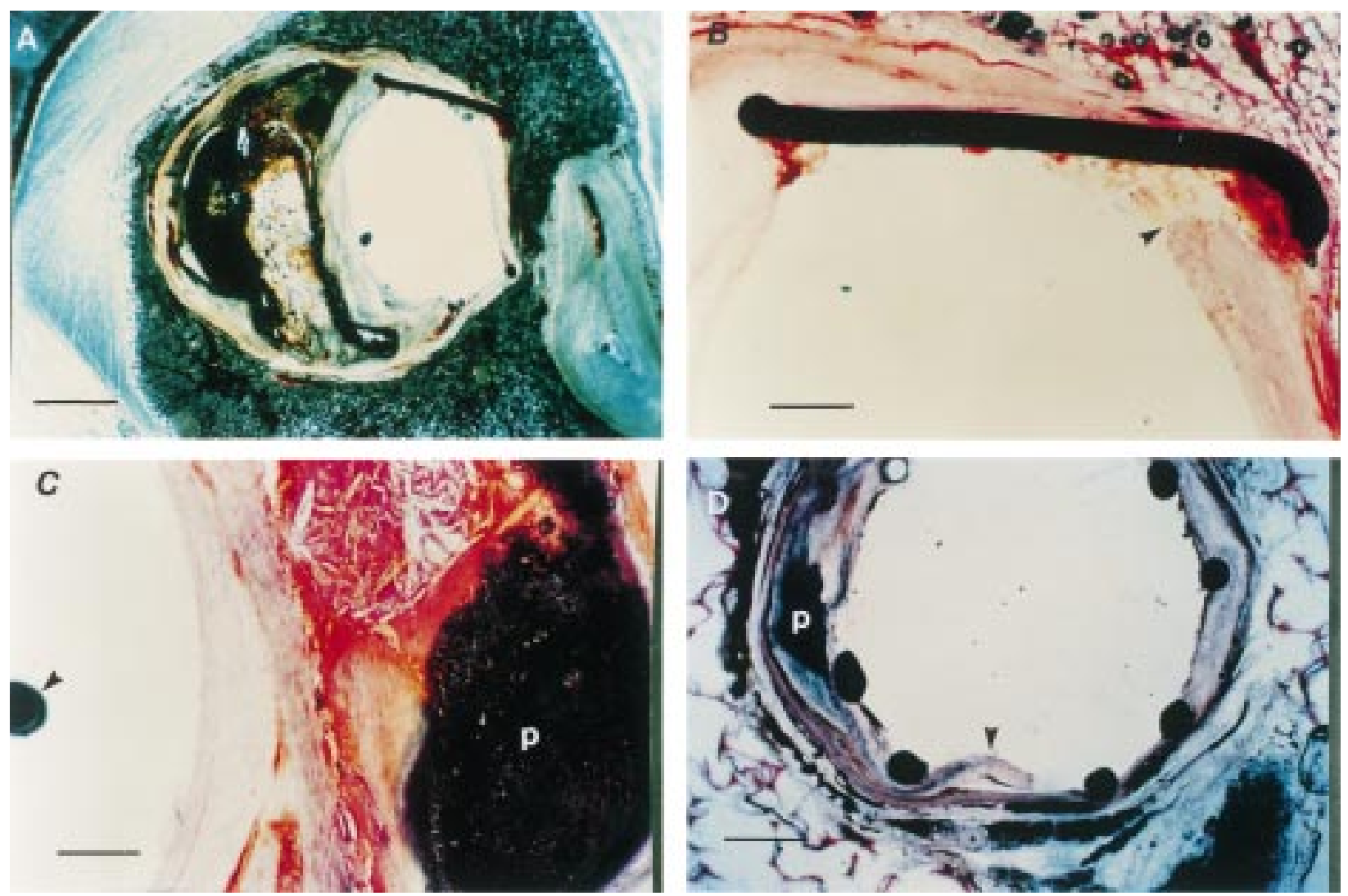

Figure 4 Stented human arterial sections. (A) Stented left anterior descending artery (LAD) section (scale bar $=500 \mu$ m), without histological staining showing preserved arterial wall architecture with an eccentric calcified plaque and stent struts in situ. (B) Haematoxylin and eosin stained section (scale bar $=50 \mu \mathrm{m}$ ) showing the stent strut embedded into relatively normal part of the arterial wall (arrowhead). (C) Haematoxylin and eosin staining showing complex calcified plaque $(p)$ with an intact capsule (scale bar $=50 \mu \mathrm{m}$ ). Note position of the guidewire (arrowhead) in the arterial lumen. (D) Unstained LAD section, obtained at necropsy from another patient, showing preserved arterial architecture and stent struts in situ. The dissection (arrowhead) mostly involves the relatively normal area of the arterial wall. Note the adjacent calcified plaque ( $p)$.

T8100, unlike JB4, preserved morphology as well as that seen with harder resins (Epon 812, LR white, and T9100). The $5 \mu \mathrm{m}$ sections showed excellent immunohistochemical characteristics and allowed $\alpha$ smooth muscle actin, vWF, vimentin, and CD68 antigen staining. Figure 2 shows $\alpha$ smooth muscle actin and vWF antigen staining in T8100 embedded stented arteries. PCNA staining was negative.

Transmission electron microscopy

Formalin fixed T9100 and T8100 embedded specimens were amenable to TEM. The morphological detail in these sections was well preserved (fig 3). JB4 being a softer resin was unsuitable for TEM.

HUMAN STENTED ARTERIAL SPECIMENS

Sections $(5 \mu \mathrm{m})$ of formalin fixed, T8100 embedded, stented human arterial specimens (optimal sectioning and staining performed according to the aforementioned methods) showed preserved arterial architecture with the struts in situ. These sections were suitable for histological staining (fig 4).

\section{Discussion}

Study of the vascular response to stenting is limited to either paraffin embedded sections after stent removal or $50-100 \mu \mathrm{m}$ resin embedded sections with the implant in situ. Each method has limitations. Removal of stent before paraffin embedding results in loss of the normal arterial architecture. The method for sectioning methyl methacrylate embedded stented arteries has two major drawbacks. Firstly, there is considerable wastage of the specimen, with only 10-14 sections per $15 \mathrm{~mm}$ stent obtained. Secondly, while acceptable for morphometric analysis, the sections are too thick for detailed histological analysis. Attempts to achieve thinner sections causes disruption of tissue architecture and loss of struts. We identified a method for sawing and grinding in combination with appropriate embedding resin and slide mounting to produce $5 \mu \mathrm{m}$ sections, allowing detailed histological, immunohistochemical, and TEM analyses. These methods are applicable to stented human arterial specimens.

We compared the performance and suitability of two commercially available high speed saws. The Isomet 2000 precision saw and the Metaserv 2000 grinder/polisher unit produced thinner sections, with less wastage from kerf loss, than the Leica saw microtome. We described appropriate adjustments to the Isomet 2000 precision saw which minimised specimen wastage. Regular use of the dressing mechanism increased efficiency of sawing while avoiding undue damage to specimens. Grinding wastage was minimised by using increasingly fine abrasive papers, which also minimised disruption of the sections. Appropriate slide holders allowed ready control of the slides and 
facilitated grinding. These adjustments produced 10-20 $\mu \mathrm{m}$ sections while minimising disruption. Asymmetry of grinding frequently produced an uneven surface and variable section thickness. The Biothin portable grinder improved the quality of the surface and yielded $5 \mu \mathrm{m}$ sections without the need for polishing. Collectively, these refinements produced 28-30 sections per $15 \mathrm{~mm}$ stent. Some 10-20 minutes are required to produce each section from the resin block with a stented artery.

Sections often detached from the glass slides despite contact adhesive (Super-attak). Aminopropyltriethoxysilone and poly-L-lysine coated glass slides did not offer any advantage. Sections were also lost because of fragmentation of the glass slides during sawing and grinding. These problems were resolved by the use of Perspex slides with contact adhesive, allowing grinding of sections to $5 \mu \mathrm{m}$ and minimising wastage.

Glycol methacrylate resin T8100 (TAAB laboratories) was identified as the optimal resin for stent sectioning because of its strength, resistance to flushing with water, and suitability for histological and immunohistochemical techniques. T8100 is suitable for histological staining without prior deacrylation/deplasticisation. Alcohol based stains are incompatible with resin T8100, limiting the range of staining methods, although the stains tested provided all the required histopathological information.

We report the first use of immunohistochemical techniques on stented arterial sections with the stents in situ. We found $\alpha$ smooth muscle actin, vWF, vimentin, and CD68 antigens in T8100 embedded stented sections in the absence of microwave antigen retrieval or trypsinisation, although for optimal results, high concentrations of primary and secondary antibodies as well as avidin biotin complex reagents together with incubation at $4^{\circ} \mathrm{C}$ for 16-24 hours were used. Although resin T8100 preserves the antigenicity of arterial tissue similar to that reported for other tissues, ${ }^{28} 29$ PCNA staining was consistently negative. Failure to detect PCNA may be attributed to embedding and polymerisation of the resin. T8100 polymerisation is exothermic despite attempts to control temperature: the PCNA antigen is susceptible to denaturation. Moreover, T8100, like other glycol methacrylates, may mask some antigenic epitopes as it binds to the amino terminal of some amino acids, especially during polymerisation. ${ }^{29-31}$ These reasons may explain the selective loss of antigenicity. TEM permits detailed analysis of the tissue stent interface. We achieved good results despite unconventional fixation with T8100 and T9100 embedded specimens.

The new methods described here are applicable to stented human diseased arteries. This application will enhance understanding of the cellular response to clinical stenting, especially at the tissue stent interface. Furthermore, these methods will allow close evaluation of the expansion characteristics of stents in relation to different plaque characteristics (eccentric, calcified, lipid laden, or thrombotic). Such observations may lead to the development of improved stent designs.
CONCLUSION

The study of different stent designs, materials, surface coatings, and adjunctive drug treatment ${ }^{23-25}$ requires detailed histological and immunohistochemical analyses of the stented vessel, especially at the tissue metal interface with the struts in situ. Until recently, however, practical difficulties prevented such analyses. Sections of stented arteries $(5 \mu \mathrm{m})$ can be produced without loss of tissue morphology or metal wire integrity using an Isomet 2000 precision saw, Biothin grinder, glycol methacrylate T8100, Perspex slides, and contact adhesive. These sections are suitable for histological analysis and, for the first time, immunohistochemistical and TEM analyses. Our methods can be used to evaluate the cellular response to vascular implants in stented experimental and human arterial (necropsy) specimens without prior removal of the stents.

We thank Dr K Suvarna (consultant histopathologist) for technical advice and B Wagner (MLSO) for electron microscopy work cal advice and B Wagner (MLSO) for electron microscopy work
(both from the Department of Pathology, Northern General Hospital, Sheffield). We thank Biocompatibles Ltd, UK, for supplying the stents and partly funding the equipment for this plying the stents and partly funding the equipment for this
project, and Bard Ltd, Ireland, for providing the rest of the funds project, and Bard Ltd, Ireland, for providing the rest of the funds
for the equipment. We also thank I Chaplin (Buehler for the equipment. We also thank I Chaplin (Buehler
Krautkramer Ltd) for his help in modifying the saw and grinder units to our applications. We are grateful to Ms N Arnold veterinary nurse, University of Sheffield) for care of the experimental animals. We are also grateful to the Department of Medical Illustration, Northern General Hospital, Sheffield for assistance with the photographs.

1 Sigwart U, Puel J, Mirkowitch V, et al. Intravascular stents to prevent occlusion and restenosis after transluminal angioprevent occlusion and restenosis after

2 Fischman DL, Leon MB, Baim DS, et al for the Stent Restenosis Study Investigators. A randomised comparison of coronary stent placement and balloon angioplasty in the treatment of coronary artery disease. $N$ Engl $\mathcal{F} \mathrm{Med}$ 1994;331:496-501.

3 Serruys PW, De Jaegere P, Kiemeneij F, et al for the BENESTENT Study Group. A comparison of balloonexpandable-stent implantation with balloon angioplasty in patients with coronary artery disease. $N \mathrm{Engl} F \mathrm{Med} 1994$; 331:489-95.

4 Stanoian EC, King SB III. Intravascular stents, intimal proliferation and restenosis [editorial]. F Am Coll Cardiol 1992; 19:877-9.

5 Shi Y, Pieniek M, Fard A, et al. Adventitial remodelling after coronary arterial injury. Circulation 1996;93:340-8.

6 Schwartz RS, Huber KC, Murphy JG, et al. Restenosis and the proportional neointimal response to coronary artery injury: results in a porcine model. 7 Am Coll Cardiol 1992; injury: results

7 Shi Y, Fard A, Galeo A, et al. Transcatheter delivery of c-myc antisense oligomers reduces neointimal formation in a porcine model of coronary artery balloon injury. Circulation 1994;90:944-51.

8 Groves PH, Banning AP, Penny WJ, et al. The effects of exogenous nitric oxide on smooth muscle cells proliferation following porcine carotid angioplasty. Cardiovasc Res 1995; 30:87-96.

9 Groves PH, Banning AP, Penny WJ, et al. Kinetics of smooth muscle cell proliferation and intimal thickening in a pig carotid model of balloon injury. Atherosclerosis 1995;117: 83-96.

10 Bar FW, Van Oppen J, De Swart H, et al. Percutaneous implantation of a new intracoronary stent in pigs. Am Heart 1991;122:1532-41.

11 Van der Giessen WJ, Serruys PW, et al. Coronary stenting with a new radiopaque, balloon-expandable endoprosthesis in pigs. Circulation 1991;83:1788-97.

12 Palmaz JC, Windeler SA, Garcia F, et al. Atherosclerotic rabbit aortas: expandable intraluminal grafting. Radiology 1986;160:723-6.

13 Barth KH, Virmani R, Strecker EP, et al. Flexible tantalum stents implanted in aortas and iliac arteries: effects in normal canines. Radiology 1990;175:91-6.

14 Schatz RA, Palmaz JC, Tio FO, et al. Balloon-expandable intra-coronary stents in the adult dog. Circulation 1987;76: $450-7$.

15 Crochet D, Grossetete R, Bach-Lijour B, et al. Plasma treatment effects on tantalum strecker stent implanted in femoral arteries of sheep. Cardiovasc Intervent Radiol 1994;17: 285-91.

16 Tominaga R, Kambic HE, Emoto $\mathrm{H}$, et al. Effects of design geometry of intravascular endoprostheses on stenosis rate in normal rabbits. Am Heart $\mathcal{F}$ 1992;123:21-7. 
17 Van Beusekom HMM, Van der Giessen WJ, Wagenvoort $\mathrm{CA}$, et al. Histological features of a polymer endovascular prosthesis after transcatheter implantation ies. Cardiovasc Pathol 1993;2(1):41-52.

18 Robinson KA, Roubin G, King S, et al. Correlated microscopic observations of arterial responses to intravascular stenting. Scanning Microsc 1989;3:665-79.

19 Pugliarello MC, Vittur F, de Bernard B. The ultrastructure of cortical bone in young adult rabbits. F Ultrastruct Res 1973;12:209-14

20 Donath K, Breuner G. A method for study of undecalcified bones and teeth with attached soft tissues. 7 Oral Pathol 1982;11:318-26.

21 Borsboom PCF, Wolfs BHJ, Leydsman $\mathrm{H}$, et al. A machine for sawing 80 micrometer slices of carious enamel. Stain Technol 1987;62:119-25.

22 Lubbe van der HBM, Klein CPAT, van der Waerden JP, et al. A new developed sawing apparatus for direct prepara-
tion of thin sections of bone with biomaterials [abstract]. Third International Symposium on Ceramics in Medicine, Terre Haute, Indiana, 1990 .

23 Hehrlein C, Gollan C, Donges BS, et al. Low-dose radioactive endovascular stents prevent smooth muscle cell proliferation and neointimal hyperplasia in rabbits. Circulation 1995:92:1570-5.

24 Waale HEW, Van der Veen $\mathrm{FH}$, van Leeuwen $\mathrm{C}$, et al. Modulation of healthy pig coronary arteries by selfexpanding stents. F Intervent Cardiol 1996;9:45-52.
25 Laird JR, Carter AJ, Kufs WA, et al. Inhibition of neointimal proliferation with low-dose irradiation from a $\beta$-particleemitting stent. Circulation 1996;93:529-36.

26 Van Beusekom HMM, Whelan DM, Van de Plas M, et al. A practical and rapid method of histological processing for examination of coronary arteries containing metallic stents. Cardiovasc Pathol 1996;5:69-76.

27 Gunn J, Holt CM, Francis SE, et al. The effect of oligonucleotides to c-myb on vascular smooth muscle cell proliferation and neointima formation after porcine coronary angioplasty. Circ Res 1997;80:520-31.

28 Burgio VL, Pignoloni P, Baroni CD. Immunohistology of bone marrow: a modified method of glycol-methacrylate embedding. Histopathology 1991;18:37-43.

29 Casey TT, Cousar JB, Collins RD. A simplified plastic embedding and immunohistologic technique for immunophenotypic analysis of human hematopoietic and lymphoid tissues. $\mathcal{F}$ Histochem Cytochem 1988;31:183-9.

30 Takamiya $\mathrm{H}$, Batsford S, Tokunaga J, et al. Immunohistological staining of antigens on semithin sections of specimens embedded in plastic (GMA-Quetol 532). $\mathcal{F}$ Immunol Methods 1979;30:277-88.

31 Takamiya H, Bodemer W, Vogt A. Masking of protein antigen by modification of amino groups using carbobenzoxychloride (benzyl chloroformate) and demasking by treatment with non-specific protease. F Histochem Cytochem 1978;26:914-20. 